\title{
GERAÇÃO DE VALOR ATRAVÉS DO USO DE TECNOLOGIAS EMERGENTES DE TI E TA DENTRO DA ARCELORMITTAL TUBARÃO*
}

\author{
Daniel Costa Bezerra1 \\ Fernando Jose Martinelli2 \\ Leandro Rodrigues Ramos ${ }^{3}$
}

\section{Resumo}

Este trabalho tem como objetivo, fazer uma explanação sobre a aplicação de tecnologias emergentes de informação e automação no cenário de indústria, onde serão descritos casos de uso com potencial de alavancar resultados para a empresa, através do aumento de produtividade e redução de custos operacionais. Para fazer este trabalho, foram selecionados os projetos mais recentes, provas de conceito e laboratórios, onde a solução explorada possui aplicações de característica inovadora. Em seguida foram avaliados os resultados alcançados ou, nos casos de projetos não concluídos, os potenciais ganhos projetados. Desta forma pode-se avaliar e concluir que os custos de grande parte das iniciativas de apelo inovador, com foco no aumento de produtividade, trazem ganhos substanciais ao negócio, não só financeiro, mas também no quesito de segurança ao homem, e qualidade do produto ou serviço prestado.

Palavras-chave: Automatização; Tecnologias emergentes; inovação.

\section{USE OF IT AND PA EMERGING TECHNOLOGIES FOR VALUE CREATION ON ARCELORMITTAL TUBARÃO}

\section{Abstract}

This paper aims to make an explanation on the application of emerging technologies of information and automation in the industry scenario, use cases will be described with potential results for the company through increased productivity and reducing operational costs. To do this activity, the most recent projects were selected, proofs of concept and laboratories, where the solution has explored innovative feature applications. Then we evaluated the results achieved or in cases of uncompleted projects, potential projected earnings. This way you can evaluate and conclude that the costs of most innovative appeal initiatives focused on increasing productivity, bring substantial gains to the business, not only financial, but also to man safety aspect, and product or service quality.

Keywords: Automation; Emerging technologies; Innovation.

1 Bacharel em Ciência da Computação pela UFES, Administração pela FAESA e Pós-Graduado em Eng de Produção pelo IFES, Analista de TI do departamento de informática da ArcelorMittal Tubarão, Vitória, ES, Brasil.

2 Doutor em Engenharia Electrotécnica pela Universidade Nova de Lisboa, Mestre em Automação Enfase em Automação pela Universidade Federal do Espírito Santo, Engenheiro Eletricista pela Universidade Federal do Espírito Santo, Gerente de Área de Automação de Processo. Arcelor Mittal Tubarão, Vitoria, ES, Brasil.

3 Bacharel em Ciência da Computação pela UFMG, Pós-Graduado em Redes de Telecomunicações, UFMG e Eng Elétrica com ênfase em Sistemas Inteligentes para Automação, IFES. Especialista Desenvolvimento em Automação e Instrumentação. ArcelorMittal Tubarão. Vitória, ES, Brasil. 


\section{INTRODUÇÃO}

O cenário econômico dos últimos anos não tem sido favorável para a indústria siderúrgica e para as empresas continuarem competitivas a exigência da excelência operacional tem sido constante, onde vários processos são fundamentados na busca incessante de ganhos de produtividade e redução de custo.

Dentro da ArcelorMlttal Tubarão, com o intuito de se buscar uma maior sinergia na gestão e evolução do parque tecnológico da planta, TI e Automação passaram a atuar de forma conjunta em um mesmo Departamento de Tecnologia e em 2015 foi criada dentro deste departamento uma equipe de pesquisa de soluções de inovação e produtividade, devido ao forte apelo destas soluções na busca dos objetivos acima.

Um dos objetivos desta equipe de pesquisa de soluções de inovação e produtividade é de avaliar, dentre as tecnologias emergentes discutidas no mercado, qual poderia ser aplicada de forma efetiva nos processos da empresa, de forma a gerar ganhos. Neste mesmo ano também se estabeleceu na planta de Tubarão um departamento de Pesquisa e Desenvolvimento que vem atuando de maneira integrada com os especialistas de Automação na identificação e concepção de novas soluções.

Com a ajuda de outros colaboradores tanto de tecnologia como do negócio, alguns processos estão sendo identificados, e avaliados que tipos de tecnologia poderiam aprimorá-los de forma a gerar ganhos para a empresa.

\section{MATERIAIS E MÉTODOS}

Uma vez selecionado os processos, os usuários do negócio participaram do detalhamento do escopo e entendimento do mesmo, a fim de verificar todas as oportunidades de melhoria onde as tecnologias com maior apelo inovador poderiam ser aplicadas.

Após detalhamento do escopo, é então realizada uma ampla pesquisa dentro do grupo ArcelorMittal, que tem unidades espalhadas ao redor do mundo, através de um benchmarking, a fim de buscar referências de alguma empresa que já fizesse uso do tipo da tecnologia discutida e poderia passar referências.

E finalmente, também realizada pesquisa de mercado com vários fornecedores, a fim de definir os equipamentos ou prestadores de serviço mais aderentes.

Uma vez selecionada a solução, a mesma gera um projeto de avaliação ou um piloto de aplicação em pequena escala para verificação se os ganhos projetados podem ser alcançados.

\section{RESULTADOS E DISCUSSÃO}

\subsection{Impressão 3D}

Uma das primeiras tecnologias avaliadas pela equipe de Inovação foi o uso de impressoras 3D. Para avaliar a aderência deste equipamento, foi selecionado um processo na usina, o de fabricação de modelos de peças na área de Fundição. $O$ processo de fabricação dos modelos é um processo artesanal, executado por marceneiros, que fazem os modelos em madeira (figura 1). 

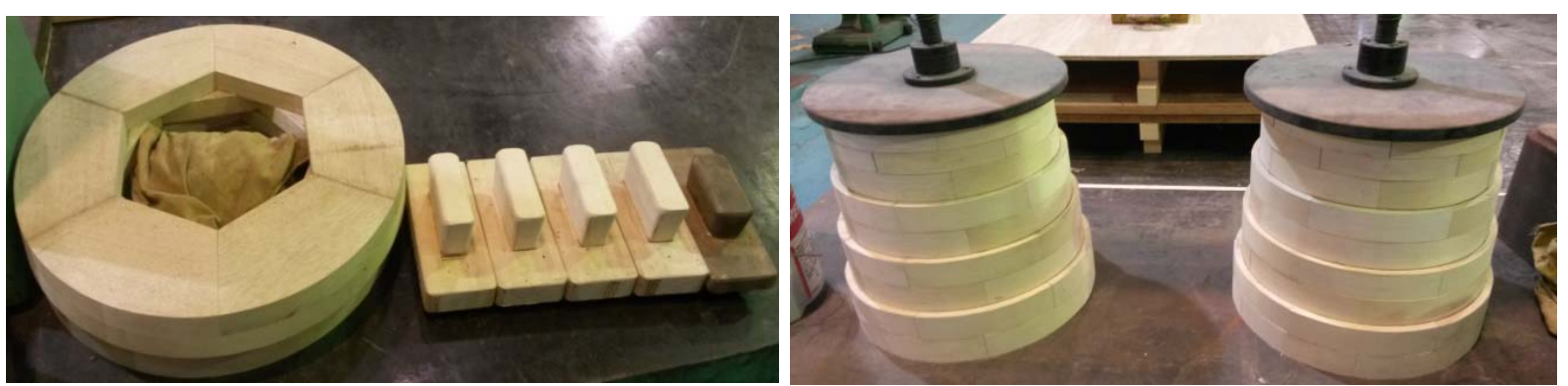

Figura 1. Exemplos de moldes em madeira

A expectativa é de que com o uso da Impressão 3D este processo se torne mais ágil, com menor custo de fabricação (mão-de-obra e materiais) e com maior precisão. Uma vez selecionado o processo aprofundou-se no entendimento sobre o mesmo a fim de se capturar os ganhos associados com o uso da tecnologia e, a partir deste detalhamento, iniciou-se benchmarks no grupo ArcelorMittal a fim de se buscar referências de uso e também pesquisas com diversos fornecedores de mercado objetivando definir um equipamento mais aderente aos requisitos já levantados, dentre eles:

- As peças tem variedade de tamanho de $10 \mathrm{~cm}$ a $2 \mathrm{~m}$ de comprimento. Tendo uma porcentagem considerável de peças com dimensões inferiores a $20 \mathrm{~cm} \mathrm{x}$ $20 \mathrm{~cm}$.

- Para peças maiores, existe a possibilidade de serem produzidas seccionadas em peças menores e posteriormente coladas.

- Como o modelo é usado no processo de fundição com areia, é necessário que o material tenha certa resistência mecânica e a calor, bem como a elementos químicos inseridos no processo.

- Existem dois colaboradores alocados com dedicação total no processo de marcenaria. Mas em alguns casos específicos, encomenda-se a fabricação do molde para fornecedores fora da planta, de acordo com o grau de urgência.

- Muitos modelos em madeira acabam sendo perdidos, devido à dificuldade de manter um processo de conservação eficiente.

A partir desta avaliação dos equipamentos pesquisados e dos custos de fabricação, por tamanho de peça, foram então selecionados três modelos que atendiam as premissas e restrições do processo, além da maior parte da produção (até $20 \mathrm{~cm}$ ). A análise de dimensão das peças produzidas é um fator muito relevante já que os custos destes equipamentos crescem consideravelmente em função do tamanho da bandeja de impressão. Os respectivos fornecedores foram então convidados a participar de uma prova de conceito onde se produziu uma peça teste para avaliação. As amostras foram então submetidas ao processo de Fundição onde foram avaliados vários aspectos da impressão como qualidade, resistência e precisão do material, além de outros aspectos como tempo de impressão.

Com o teste realizado pode-se concluir que realmente o uso da impressora 3D pode substituir o trabalho do homem na produção da peça, minimizando os riscos inerentes à atividade, incrementando a produtividade e reduzindo custos de materiais. 

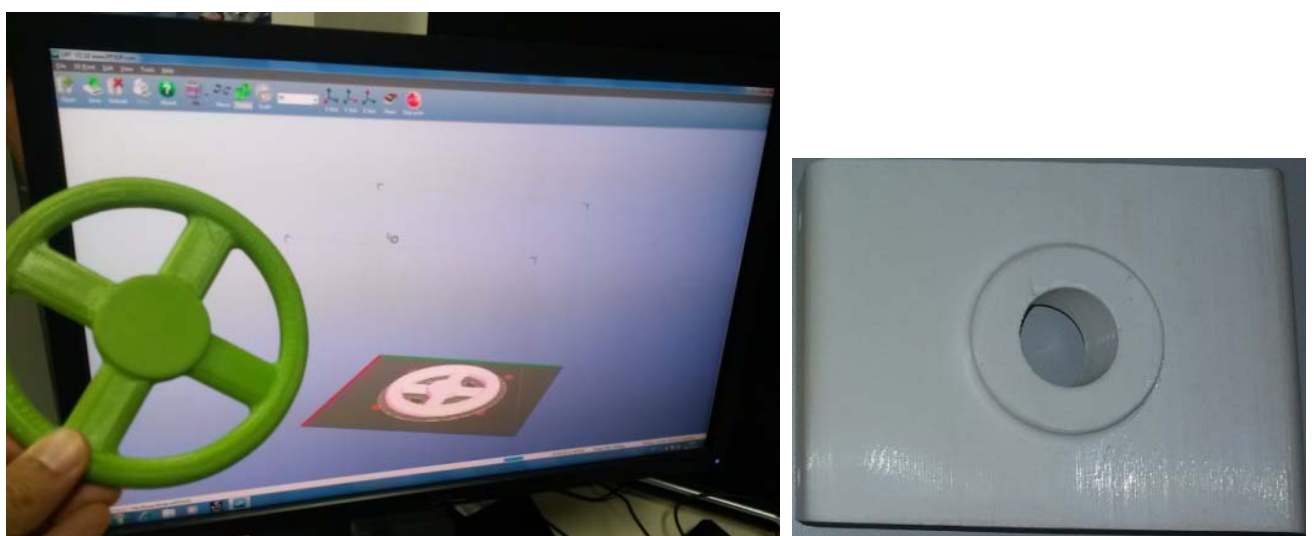

Figura 2. Exemplos de modelos já impressos e utilizados no processo

\subsection{Analytics e Big Data}

Técnicas computacionais para análises estatísticas de dados já vem sendo aplicadas ao longo dos últimos anos nas organizações. O surgimento de novos frameworks para tratativa de grandes volumes de dados em computação distribuída, associados a uma disponibilidade cada vez maior de poder computacional vem promovendo investimentos nas empresas para o uso mais intenso destas técnicas no contexto de seus processos. Aliado a este cenário vemos as grandes empresas de software inserindo em seus enxovais de soluções e serviços, frameworks analíticos cada vez mais poderosos para tratativa de dados, estruturados e não estruturados, hospedados na empresa ou na computação em nuvem.

$\mathrm{Na}$ ArcelorMittal Tubarão uma estratégia vem sendo desenvolvida para tratativa deste tema onde busca-se através de provas de conceito avaliar a aderência destas técnicas aos processos corporativos e industriais da planta. Outro aspecto que vem sendo discutido e de como difundir uma cultura analítica no contexto da usina, o que envolve aspectos como formação profissional (figura do analista de dado) e uma maior independência dos usuários de negócio para tratativa dos dados. Seguindo nesta linha de raciocínio é importante também avaliar o potencial dos softwares envolvidos no que diz respeito à facilidade de uso, capacidade de se extrair e manipular dados de diversas bases de dados e a eficiência dos algoritmos de data mining ofertados.

Como exemplo de caso de uso na ArcelorMittal Tubarão, está se avaliando a utilização da técnica para identificação de esfoliação em bobinas. Esfoliação é um defeito superficial observado no material laminado no LTQ (Figura 3), podendo ter origem na aciaria ou laminação. São causadas principalmente por impurezas contidas no aço durante as etapas de refino e lingotamento contínuo. Este defeito pode ser de natureza química (arraste de pó fluxante, arraste de escória da panela/ distribuidor, desoxidação/reoxidação do aço, arraste de refratário, etc.) ou mecânica (defeitos em placa, tais como trincas superficiais, arranhão e cristas de escarfagem), ou de origem de laminação. Dados de diversos sistemas envolvidos no processo (Nível 1 a Nível 3) foram coletados, transformados e analisados por ferramental analítico (Figura 4) onde já se tem resultados preliminares que apontam para uma aderência do método ao processo. 

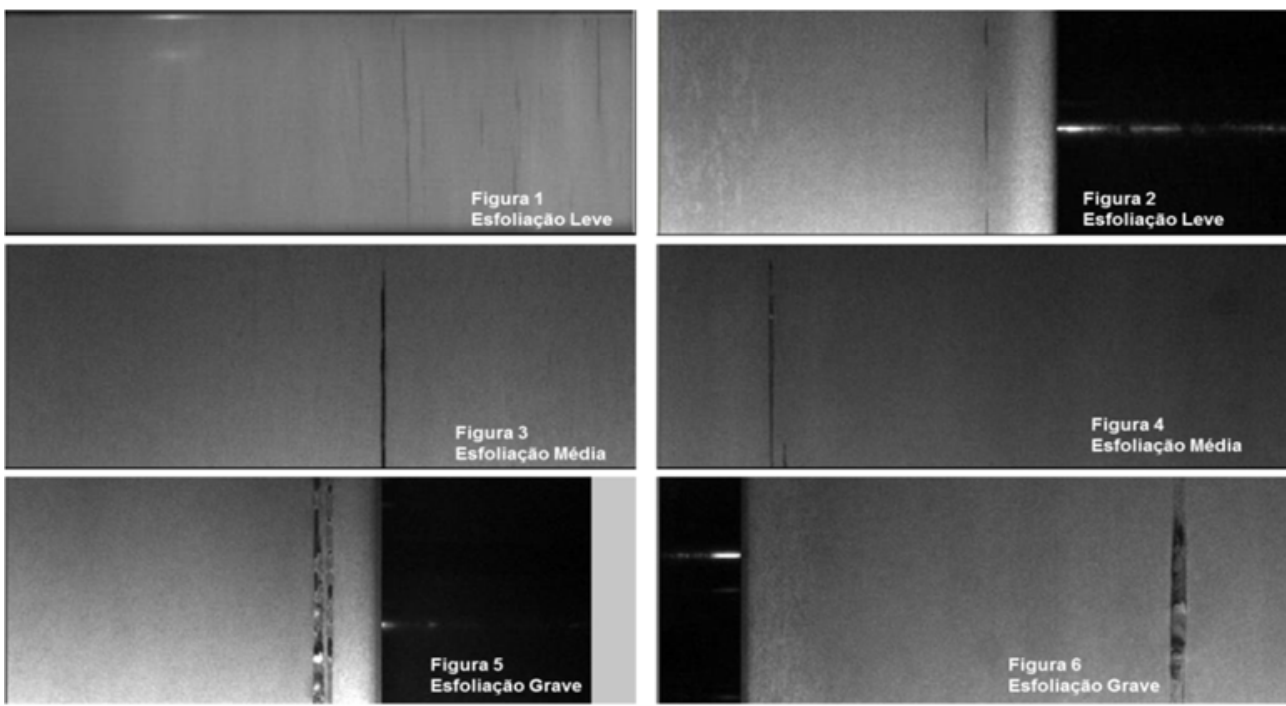

Figura 3. Exemplos de esfoliação em laminados (leve/média/grave)

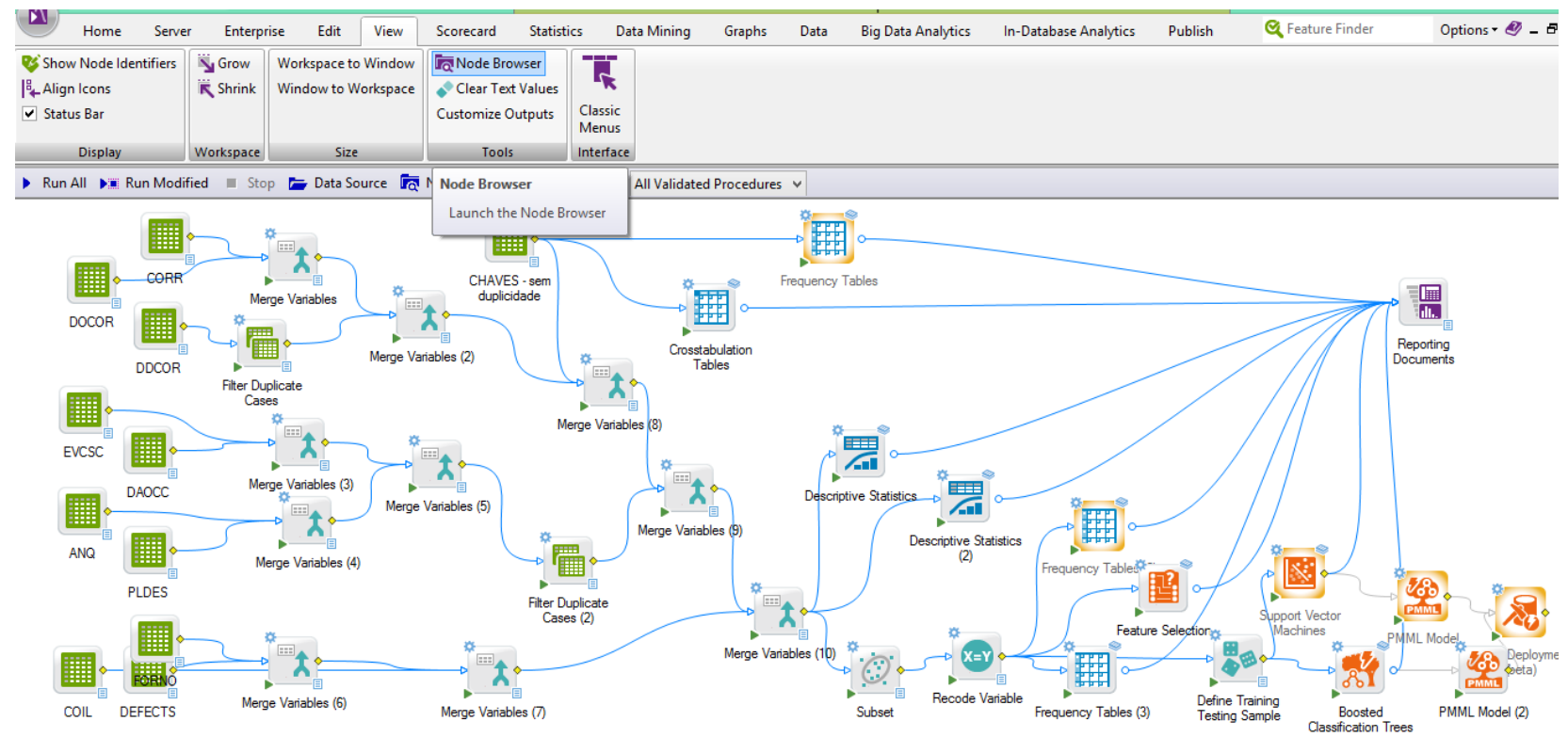

Figura 4. Exemplo de modelagem analítica utilizada par análise da esfoliação.

\subsection{Mobilidade}

O uso de dispositivos e sistemas combinados em soluções de mobilidade, talvez seja uma das tecnologias emergentes com maior número de possibilidades e oportunidades no cenário de inovação. As aplicações são muito diversificadas e muitas vezes de baixa complexidade, permitindo rápida implantação, uso e apuração de resultados.

No cenário industrial o uso de mobilidade não é novidade (Exemplo: Coletores), contudo, com a evolução de uso de tablets, smartphones e linguagens de desenvolvimento híbridas, como HTML5, as soluções ganharam um novo patamar de robustez promovendo a inserção dos novos dispositivos móveis no contexto de chão-de-fábrica.

$\mathrm{Na}$ ArcelorMittal, este cenário já se faz presente em várias iniciativas, na busca de ganhos de produtividade, segurança, confiabilidade da informação e maior mobilidade para os profissionais. 


\subsubsection{SAP FIORI - Aprovações de documentos}

Processos muito comuns nas grandes empresas, os fluxos de aprovação de documentos, seja de compras ou vendas, fazem parte da carteira de atividades dos executivos. Como este processo necessita ser devidamente estruturado, para atender normas de regulamentação, padrões e auditorias, todo ele, normalmente é realizado de forma sistêmica, obrigando o usuário a ter acesso ao computador sempre que precisa aprovar um documento.

O problema é que nem sempre o executivo está em mãos com um desktop ou notebook, o que pode, às vezes, atrasar o processo, além de ser um incômodo para estes profissionais de nível gerencial.

Nada mais prático que poder fazer estas aprovações pelo smartphone, não importa o lugar e horário, gerando um conforto e agilidade muito maior, sem denigrir em nada a confiabilidade e integridade do processo.

$E$ isso se tornou possível na ArcelorMittal Tubarão graças a implantação da solução SAP FIORI, solução que funciona integrada ao ERP SAP da companhia, que permite agora que documentos de requisição e ordem de compras, contratos, folhas de serviço e ordens de venda sejam avaliados, aprovados ou não com poucos toques pelo telefone celular.
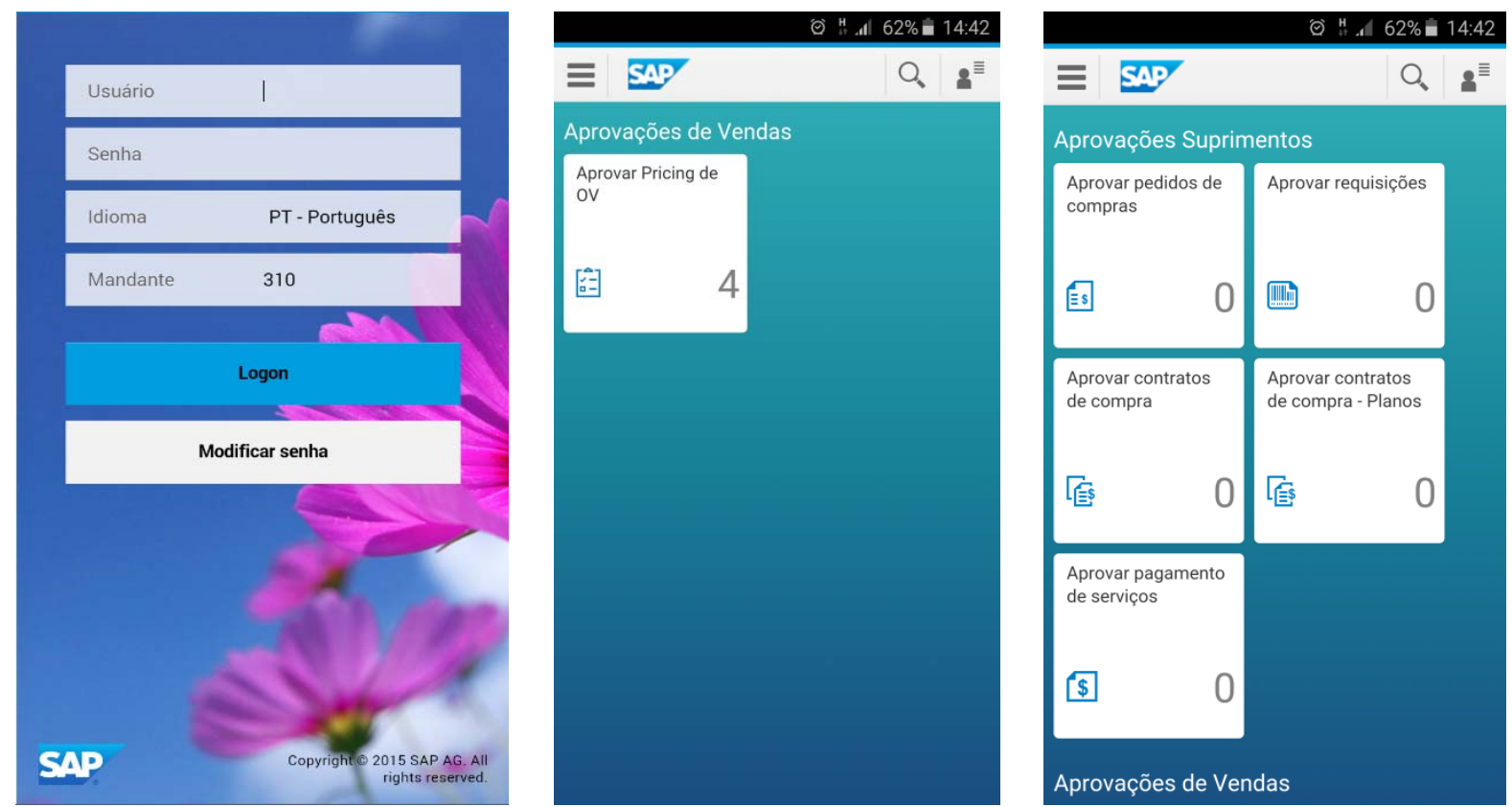

Figura 5. Telas de login e aprovações de documento a partir do smartphone

\subsubsection{Manutenção}

Entre os potenciais processos candidatos para ganhos de produtividade pelo uso de mobilidade, as manutenções mecânicas e elétricas se destacam, sem falar do processo de estocagem de materiais. Processos estes de suma importância para as grandes empresas, que geram volumes relevantes de custo recorrente, apresentam, na maior parte dos casos, vários pontos de retrabalho e risco: uso de papel com checklists para verificações ou cadernos de anotações e posterior passagem a limpo para sistemas, dificuldade de identificação de equipamentos (descrição x aparência), acesso a locais com grau de risco, controle manual de entrada, saída e armazenagem de materiais, etc.

Alguns destas atividades já faziam uso de coletores de dados, a fim de buscar um processo mais otimizado. Contudo, na busca constante de atualização, 
recentemente a ArcelorMittal Vega (outra filial do segmento de Aços Planos) implantou no papel de coletor o uso do IPHONE 5S, combinado com um case, que potencializa várias características do smartphone como coletor, a citar a leitura de código de barras, extensão de bateria e proteção. Este dispositivo, combinado com uma solução sistêmica integrada ao ambiente SAP, permitiu uma modernização de algumas tarefas, que deram um novo significado as atividades de manutenção.
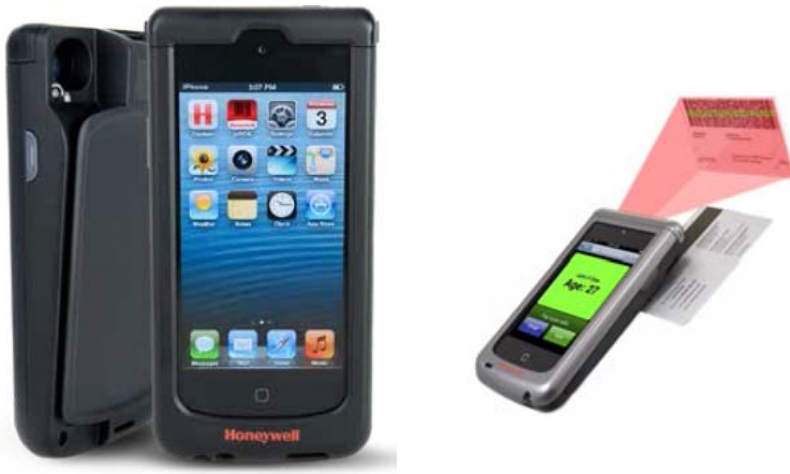

Figura 6. Combinação do IPHONE com o case leitor criaram um coletor de alto potencial

Através do uso deste dispositivo, os colaboradores podem apenas ler os códigos de barra dos equipamentos, que serão identificados automaticamente e seguir as instruções na tela do dispositivo e já dar o parecer na hora. Poderão dar entrada e saída de materiais em estoque ou identificação da posição física dos mesmos. Entre outras funcionalidades que exigiam que o colaborador se deslocasse até um computador para registro, poderão ser feitos de qualquer lugar da usina.
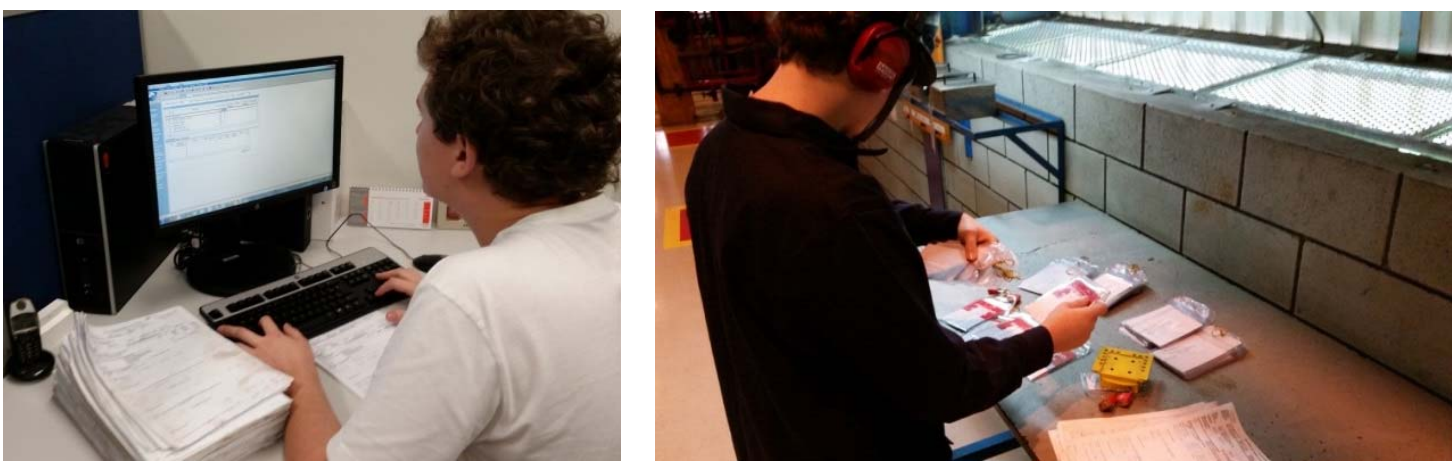

Figura 7. Trabalhos manuais executados antes da implantação da solução
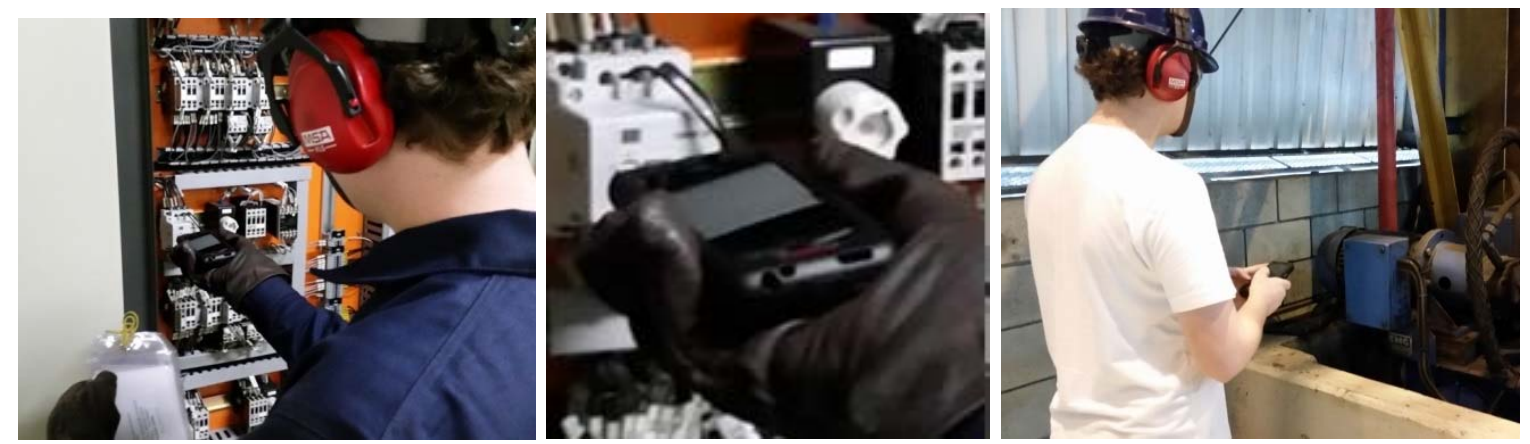

Figura 8. Trabalhos executados após da implantação da solução 
Ainda no contexto da manutenção a ArcelorMittal Tubarão também criou um aplicativo piloto para atender ao processo da inspeção preditiva em suas linhas de acabamento, que funciona integrado a atual aplicação de gestão da manutenção da empresa, o SISMANA.
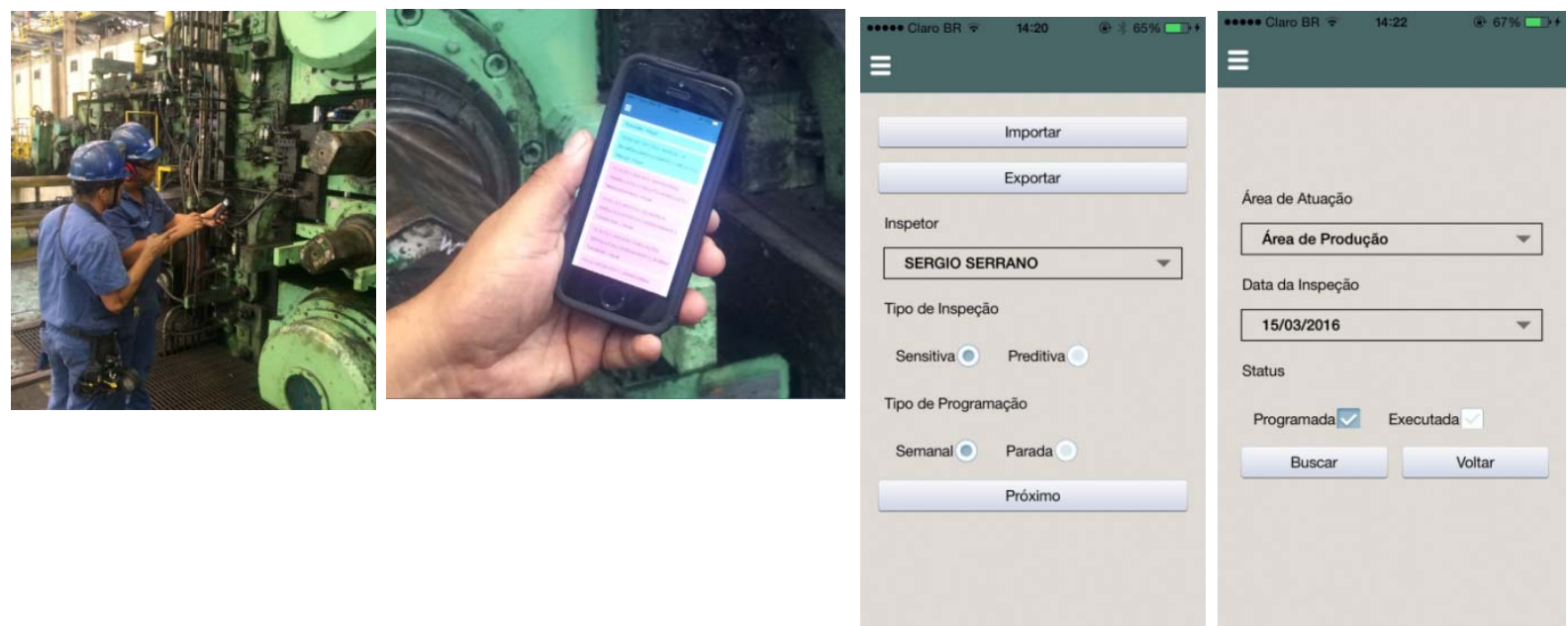

Figura 9. Aplicativo SISMANA Mobile

Esta prova de Conceito tem por objetivo aumentar a confiabilidade e a produtividade nas atividades de inspeção elétrica e mecânica além de expressiva redução no uso do papel pelas áreas de manutenção. A figura 10 apresenta um estudo realizado sobre a potencial economia de papel associada às inspeções sensitivas e preditivas na planta.

\begin{tabular}{|c|c|c|c|c|c|c|c|c|c|c|c|c|c|c|c|}
\hline & Ano & 2015 & 2015 & 2015 & 2015 & 2015 & 2015 & 2015 & 2015 & 2015 & 2015 & 2015 & Média Mensal| & Pontos por & Páginas Impressas \\
\hline & Mês & 1 & 2 & 3 & 4 & 5 & 6 & 7 & 8 & 9 & 10 & 11 & & Página & por Mês \\
\hline \multirow{3}{*}{ Usina } & $\begin{array}{l}\text { Pontos de Inspe ção } \\
\text { Sensitiva }\end{array}$ & 421167 & 369277 & 409672 & 405266 & 403387 & 423084 & 454673 & 395485 & 417462 & 423561 & 369368 & 408400 & 20 & 20420 \\
\hline & $\begin{array}{l}\text { Pontos de Inspe ção } \\
\text { Preditiva }\end{array}$ & 26846 & 22071 & 30192 & 27783 & 25736 & 27457 & 28535 & 28078 & 27611 & 26165 & 26603 & 27007 & 10 & 2701 \\
\hline & & & & & & & & & & & & & & TOTAL & 23121 \\
\hline
\end{tabular}

Figura 10. Potencial redução no uso do papel

Buscou-se manter para esta aplicação o mesmo alinhamento tecnológico, fazendo uso de dispositivos IPHONE 5S (ao invés de coletores tradicionais). Pretende-se com as melhorias futuras já previstas explorar ainda mais o potencial destas plataformas móveis, como exemplos:

- Implementação e verificação das rotas de inspeção (com uso do GPS).

- Uso de TAGs NFC para identificação de equipamentos.

- Integração com sistemas de gestão de documentos para visualização online de procedimentos técnicos.

\subsection{Drones}

Outro exemplo de tecnologia emergente já presente na ArcelorMittal Tubarão, são os Drones. Apesar da tecnologia em si não ser nada nova, as aplicações de uso do mesmo tem mais caráter de novidade.

Como o uso difundido de Drones vem se estendendo rapidamente, a ArcelorMittal Tubarão, na preocupação de fazer uso de forma responsável da solução, criou um padrão de uso, que rege normas seguindo as principais regulamentações 
governamentais, preserva normas de segurança interna, como preocupações com risco ao homem e danos a equipamentos; e ainda faz uma homologação do fornecedor e piloto do equipamento, para certificar habilidade de uso do mesmo.

Ainda está em discussão o melhor modelo de utilização desta tecnologia e todas as oportunidades de aplicação, mas até o momento a ArcelorMittal Tubarão já teve alguns casos de sucesso de uso com empresas parceiras, que possibilitaram ganho de tempo na execução de atividades, e redução de exposição ao risco pelo homem, como demostrados nas figuras abaixo.
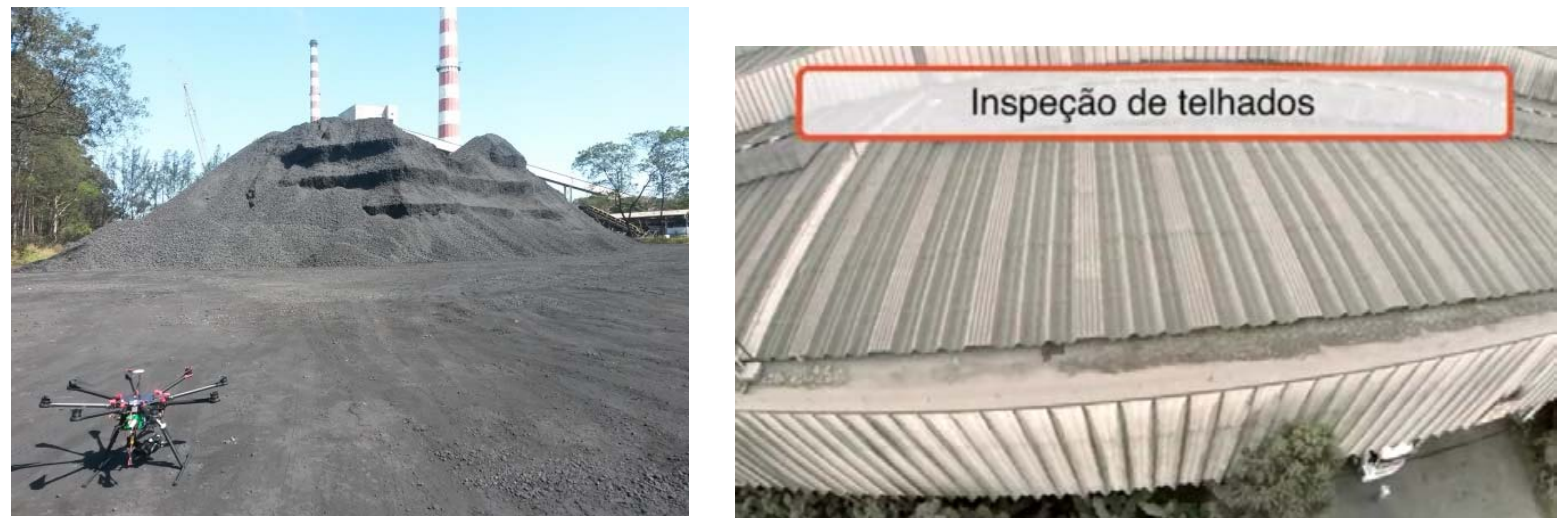

Figura 11. Medição de pilha de coque e imagens capitadas pelo Drone na inspeção de telhados

\subsection{Visão Computacional}

Uma vertente que vem crescendo na ArcelorMittal Tubarão é o processamento digital de imagens relacionadas processo produtivo. A interpretação destas imagens associadas a algoritmos inteligentes vem proporcionando o desenvolvimento de soluções para otimização de processos, gerando resultados positivos em termos de ganho produtividade e redução de custos. Um exemplo de caso foi aplicado no processo de escumagem da Aciaria para controlar o teor de enxofre no gusa. Este processo de é conduzido por um operador, fazendo assim com que a qualidade do processo fique relacionada diretamente à pessoa que opera a máquina. Desenvolveu-se então o sistema viSlag que julga o momento adequado de parada do processo através de medições por câmera, e auxilia na discriminação das áreas de interesse para facilitar a rotina do operador (Figura 12). Com esta solução buscase diminuir a variação de resultados do processo, reduzindo a reincorporação de enxofre de 45 ppm para 35 ppm, gerando economia na faixa de \$800k/ano em agente dessulfurante para a panela de aço. Adicionalmente melhora-se a condição de trabalho do operador, provendo uma ferramenta de tratamento da imagem para discriminar o alvo a ser retirado, e transferindo a decisão do fim de tratamento para o sistema. Além deste caso, outras iniciativas já vêm sendo alavancadas em conjunto com o departamento de P\&D para atender a novas demandas como inspeção de carcaça de convertedor, análise de camber e planicidade, classificação de sucata, análise dimensional de produtos, impressão digital de tarugos dentre outras. 


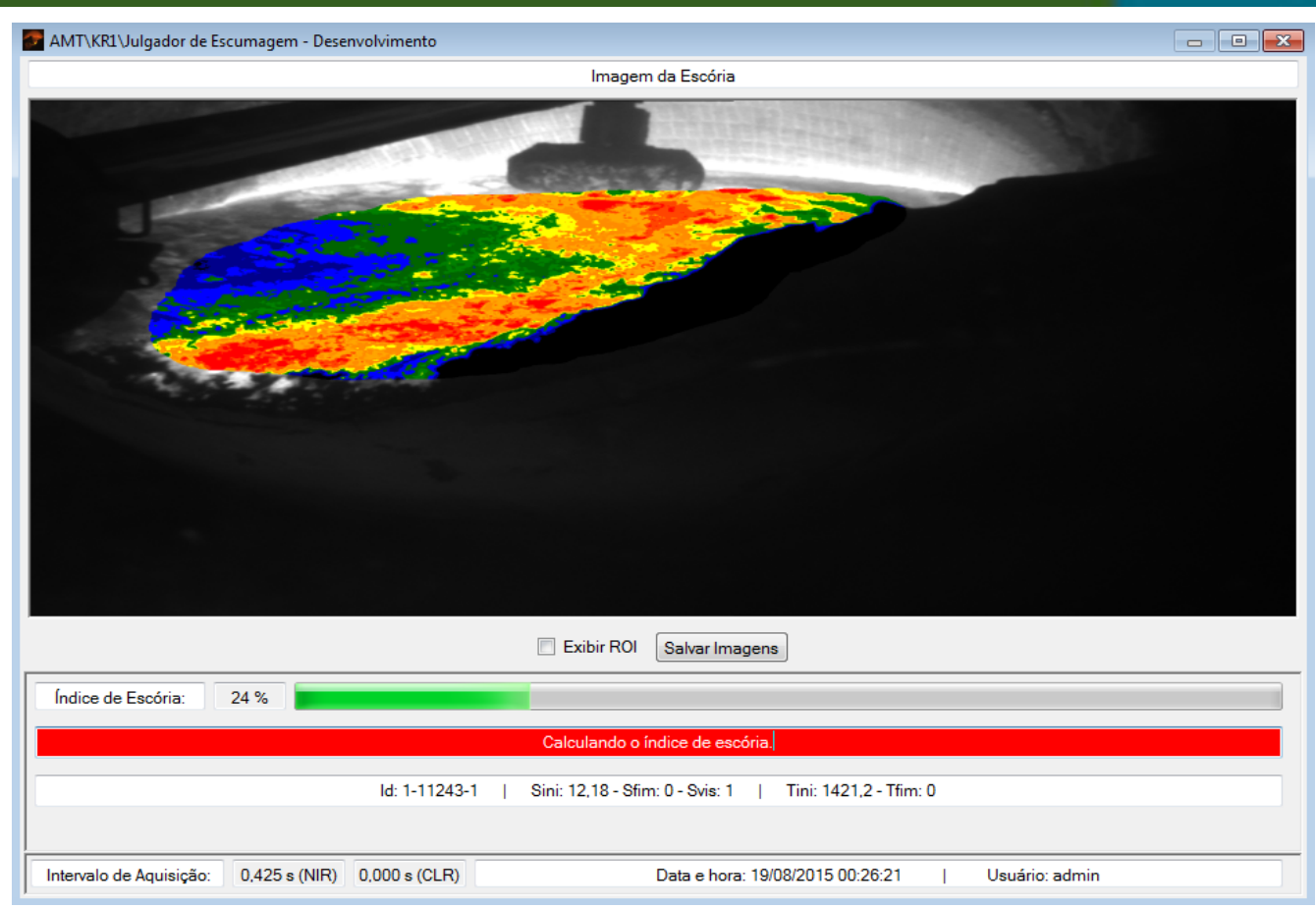

Figura 12. Tela principal do sistema viSlag

\subsection{Trabalhos Futuros}

Os exemplos contidos neste trabalho endereçam tecnologias que já vem sendo experimentadas na ArcelorMittal Tubarão. Adicionalmente novas tecnologias emergentes estão sendo avaliadas no intuito de se capturar ganhos de produtividade no processo, dentre elas citamos:

- Uso de Internet das Coisas (IIoT - Industrial Internet of Things) para sensoriamento e localização de veículos nas plantas do grupo (Caminhões e Locomotivas).

- RFID para identificação de materiais e apoio a processos logísticos.

- Simuladores de pontes-rolantes para otimizar a capacitação de profissionais e consequente redução de risco operacional inerente à atividade.

- Robotização aplicada nas Oficinas de Fabricação de Peças associada a produção de moldes e soldas.

\section{CONCLUSÃO}

Como citado na sessão anterior, algumas tecnologias podem não ser tão inovadoras, mas a aplicação das mesmas sim.

Logo, no mercado altamente competitivo em que a siderurgia se encontra, a ArcelorMittal busca a todo momento projetos de ganho de produtividade. Daí, a escolha dos processos e recursos adequados, além da combinação das tecnologias com as soluções de automação e de sistemas assertivas, faz toda a diferença na geração de melhores resultados.

Alguns dos casos de uso citados como da impressora 3D, soluções de mobilidade e uso de Drones, já trouxeram ganhos efetivos, tanto financeiros, como de minimização de risco ao negócio, ao homem e maior produtividade. Mas outros apresentados em fase de discussão, avaliação e implantação tem grande potencial. 
Apesar das tecnologias aplicadas não serem o principal core business da empresa, concluiu-se, que mesmo num papel inicialmente acessório, acaba tendo papel estratégico e gerando grande valor a cadeia de suprimentos da companhia, o que justifica incentivar um perfil empreendedor e inovador dentro das equipes de TI e TA.

\section{REFERÊNCIAS}

1 Oliveira CJM, Dalmaso R, Furtado H. Slag Skimming Judgment Gauge Development at Arcelormittal Tubarao. ABM Week.2015. 